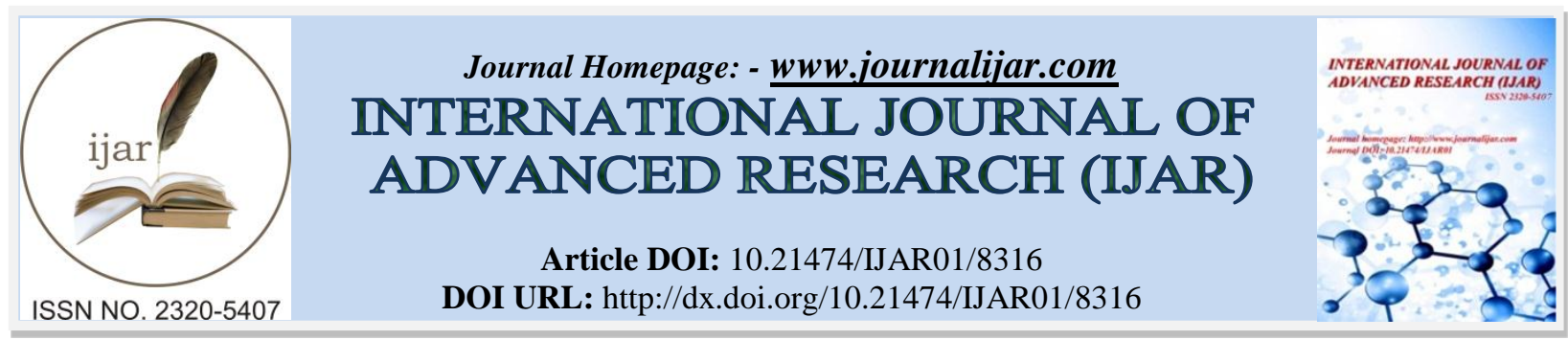

RESEARCH ARTICLE

\title{
USING EMOJIS IN IMPROVING NARRATIVE WRITING.
}

\author{
Grissilla Sarawa Anak Francis Drahman ${ }^{1}$, Claressa Joachim², Syaneezah Binti Mohd Rahim³, and Melor Md \\ Yunus ${ }^{4}$. \\ 1. Sk Rumah Essau, Sarawak. \\ 2. Sk Kungkular, Sabah. \\ 3. Sk Kem Tentera, Sabah. \\ 4. Faculty of Education, Universiti Kebangsaan Malaysia (UKM).
}

\section{Manuscript Info}

……………………

Manuscript History

Received: 04 November 2018

Final Accepted: 06 December 2018

Published: January 2019

Keywords:

Narrative Writing, Emojis, English

Language Learning, Education,

Teaching.

\section{Abstract}

Writing lessons are often perceived as boring and difficult for the young learners. The pupils found words were difficult to be comprehended easily. Previous studies showed that young learners understand better through the use of visual aids. The wide usage of pictographs of faces, objects and symbols known as emojis in electronic messages has seemed to gain attention. Instead of using emojis to express emotions and ideas, this innovation attempted to improvise its use for writing lessons. Therefore, this action research aimed to explore the effectiveness of using emojis in improving narrative writing among Year 4 pupils. The samples consisted of 35 pupils with low level of English language proficiency selected from three primary schools located in Bekenu, Sarawak; Tenom and Sandakan, Sabah in Malaysia. Data was collected and triangulated both qualitatively and quantitatively using pre-test and post-test, questionnaire and interviews. Then, the interview and questionnaires were tabulated while the pre and post-tests results were analyzed using inferential statistics. It was found in the results that the pupils enjoyed the writing lessons and able to write better sentences. In conclusion, the intervention of using emojis in a modular approach found to be effective in improving narrative writing for low English language proficiency to certain extent.

\section{Introduction:-}

The rise of the usage of technologies in human life today upsurges the needs to be able to communicate through writing. According to UNICEF (2017), digital technology has already changed the world and as more and more children go online around the world, it is increasingly changing childhood. Hence, this allows digital conversation to take place in the world today. Lo (2008, as cited by Tigwell \& Flatla, 2016) explained even though the digital conversations are governed by the text, non -verbal conversational cues such as emoji help to express emotional expressions and determine the senders' meaning to improve the efficiency of the conversation.

Fischer (2003) stated that humans have always needed to communicate, and in particular, communicate their 
feelings and emotions to one another, either as a protection or sharing device and throughout history have used pictures or symbol to achieve this and create visual connections with one another. Emojis are well known in the social media such as Facebook, Instagram, WhatsApp and so on where children are well exposed and using the emojis on daily basis. According to Stark and Crawford (2015), emojis are popular digital pictograms that can appear in text messages, emails, and on social media platforms. They added that the characters are generally understood and have a rich and complex socioeconomic history. Danesi (2017) described emoji as an English adaptation of a Japanese word that means 'picture' and 'letter, character' and it becomes a necessary for the digital messaging. Swiftkey (2015) stated that the use of emoji is to add an affective tone to text messages, or else to suggest refinements to the specific parts of the messages' content.

In Malaysian primary schools, pupils are exposed to the early stage of learning English as a second language (ESL) in both primary and secondary schools. Nevertheless, learning the language is not an easy task. In order to master it, learners have to be adequately exposed to all the four basic skills, namely listening, speaking, reading and writing. In writing, pupils started with the word level, moving further to the sentence level and continue to the completion of short essays. According to Tindal and Marson (1990), a writer must be able to develop writing towards the needs of the target group, thus this requires different skills such as academic writing or narrative writing skill. However, the standards of English among Malaysian pupils show not much improvement despite of learning English for several years, especially on writing skill. It is found that in Malaysian schools, writing a narrative essay can be challenging and difficult.

Several studies on written works of Malaysian ESL learners have shown that their writings are full of mistakes and writing lesson is often regarded as difficult. Berkel (2004) discussed English language beginners' level learners and how they lack the necessary prerequisites for a phonological strategy. In a study conducted by Haq (2001) evaluating students' narrative writings in terms of dimensions of ideas, organization, voice, word choice, fluency and writing convention, the findings indicated that students did better for ideas and organizations, but they have problems in writing conventions. That is supported by Zakaria, Yunus, Nazri, \& Shah (2016) mentioned that writing is likely to be a challenging task for ESL students who are easily bored with the conventional approach. They added that it is also a painstaking process for some pupils that have difficulties in expressing themselves well in writing. Therefore, narrative writing tasks can be very difficult and boring for the students. For a writer to be able to write effectively, he or she must be able to develop writing towards the needs of the target group, thus this requires different skills such as academic writing or narrative writing skill (Tindal \& Marston, 1990). With that, this research paper exempted to explore the usage of emojis to improve narrative writing among Year 4 pupils with low level of English proficiency. The research development, methodology, results, findings, implication and suggestions will be further discussed in this article.

\section{Literature Review:- \\ Visual aids}

Past studies attempt to prove visual aids able to assist in the learning of writing skill in ESL classroom. Through the emojis module, it allows pupils to develop their understanding without restriction. The meaning can be varying, as long as it is relevance. Thus, picture series of emojis form wide possibility for pupils to improve their writing and their creativity to write a narrative story. According to Piaget (1963, 1983, as cited in Noriati, Boon \& Wong, 2010), experience of the children will help in constructing knowledge for them. The picture is the one that can give experience and help children to construct knowledge from their prior experience. This supported that the use of emojis able to assist knowledge acquisition among them.

An emojis' module was developed to provide multimedia visual for the pupils that mostly have lower chances to have access to internet. This module granted opportunities for these pupils to familiarize themselves with emojis and equip themselves with necessary skill in 21 st century where digital communication not mereley just text but also emojis to help to express emotional expressions and determine the senders' meaning to improve the efficiency of the conversation (Lo, 2008 as cited by Tigwell \& Flatla, 2016).

Yunus et al (2012) agreed that digital comics enable teachers to help low achieving language learners to write in English. However, there were limitation that held the research respondents to apply ICT in the classroom. The respondents perceived the use of digital comics in the classroom requires a lot of time and impractical to schools that have zero access to the necessary facilities. With regard to the research, the emojis module were created in such a way that teachers may using it if there are necessary facilities such as internet and the computer lab in their school 
and also for schools that situated in rural areas. This production of the module is in line with the vision to provide equal education right to all pupils regardless their race, age and location.

\section{Emojis from Social Networking Services (SNS) in ESL classroom}

The learning of language has gone beyond the boundaries of classroom. This is proven through previous studies which revealed the usage of SNS in ESL classroom befitted learners in various ways. Nur Ehsan et. Al (2013) found that that the participants have positive perceptions and attitude in using blog to improve English writing skills. This is supported by Yunus, Salehi \& Chenzi (2012) that disclosed that integrating social networking services in ESL writing classroom could help to broaden students' knowledge, increase their motivation and build confidence in learning ESL writing. One similarity from these SNS is that all have emojis features.

As for that, emojis modules were produced by taking these into consideration. It is widely known that emojis exist in SNS. Rather than by just using emojis as a communication tools, teachers are able to access to emojis module to guide them on how to use emojis to help the low proficiency pupils to improve their narrative writing skill. Through the module, teachers may use in online or as realia in class where it permits pupils to interact with real-life situation where emojis are widely use among the society today.

The usage of SNS in helping teaching and learning is limitless. For example, Yunus and Salehi (2012) figured that about two thirds of the respondents agreed that Tumblr, as one of the social networks, can be used as an effective medium in teaching writing skills. However, some limitations might prevent teachers from using Tumblr as an effective tool in teaching and learning. Another research by Yunus and Salehi (2012) showed that 'Facebook groups' is an effective tool in improving the students' writing skills, especially in the brainstorming of ideas before the actual writing. The emojis module guide not only pupils but also the teachers to develop understanding to suit the low proficiency pupils where the module started with the word level towards sentences and paragraph level. For the low proficiency pupils, this prevent their withdrawal in a writing lesson as less people know their errors as it is not posted online for everyone to see.

\section{Methodology:-}

\section{Research Design}

The study is an action research as it allows getting insiders' viewpoint on the learning issues and the pupils' writing progresses (Abraham, 2015). The Kemmis and McTaggart Model for action research is used that comprises the steps plan, act, observe and reflect (Kemmis, McTaggart \& Retallick, 2004). This is depicted by looking into whether emojis has helped in the narrative writing. In the planning step, the intervention was chosen along with the right instruments to measure. Then, the intervention was conducted as the step in acting. Next, in the observing step, the results of the pupils were observed. Lastly, the results were analyzed to see if the results have reflected improvements or not. The research employed triangulation of data where both qualitative and quantitative data can be combined and compared from questionnaires, semi-structured interviews and pre and post-test.

\section{Respondents}

A total of 35 Year 4 low English language proficiency pupils were elected from three primary schools located in Bekenu, Sarawak (10 pupils); Tenom (10 pupils) and Sandakan (15 pupils), Sabah. The respondents were 20 males $(57.14 \%)$ and 15 females $(42.86 \%)$. All the respondents were 10 years old.

\section{Procedure}

Before the intervention was conducted, a pre-test on writing were held. Then, all 35 pupils were asked to answer a questionnaire form. The intervention was conducted in 3 weeks using an emoji module which contained exercises for the pupils to complete. In week 1, Module 1; WordTube was introduced. In this module, pupils were introduced to emojis and the vocabularies the emojis depicted. The pupils learnt to classify words into verbs, nouns and adjectives. After that, Module 2 which called as WordStagram were conducted in Week 2. This module helped the pupils to learn the sentence structures and learn to construct sentences using emojis. Using one emoji to represent each of the sentence structures of Subject + Verb + Object (SVO), pupils tried to understand and write the sentences correctly. Then, in the third week, WordsApp of Module 3 was conducted. This phase allowed pupils to use emojis in order to represent their words and write a narrative writing. Finally, a post-test on writing were given to all 35 pupils in three schools. A total of 9 pupils were interviewed; three pupils respectively from each school. A set of questionnaires was given to all 35 pupils to answer to gain their opinions on the intervention conducted in this research. 


\section{Data Analysis}

The pre-test and post-test results were analyzed using inferential statistics while the interviews and questionnaires were analyzed thematically. All respondents were coded A1, A2 and so on for School A. For School B, respondents were coded as B1, B2 and so on. Respondents from School C were coded as C1, C2 and so on. Pseudonyms were used for the interviewees.

\section{Results and Discussions:-}

This section presents the data collected related to the usage of Emojis Module to improve narrative writing skill among Year 4 pupils with low proficiency level. The data collected suggested that using emojis in teaching narrative writing is very helpful for the pupils. Results collected from the pre and post-tests, questionnaires and interviews showed that there is an improvement in pupils' narrative writing when teacher use the emojis modules.

\section{Test}

Fig 1:-Analysis of Achievement Levels for Pre-test and Post-test

\section{Analysis of Achievement Levels for Pre-test and Post -test}

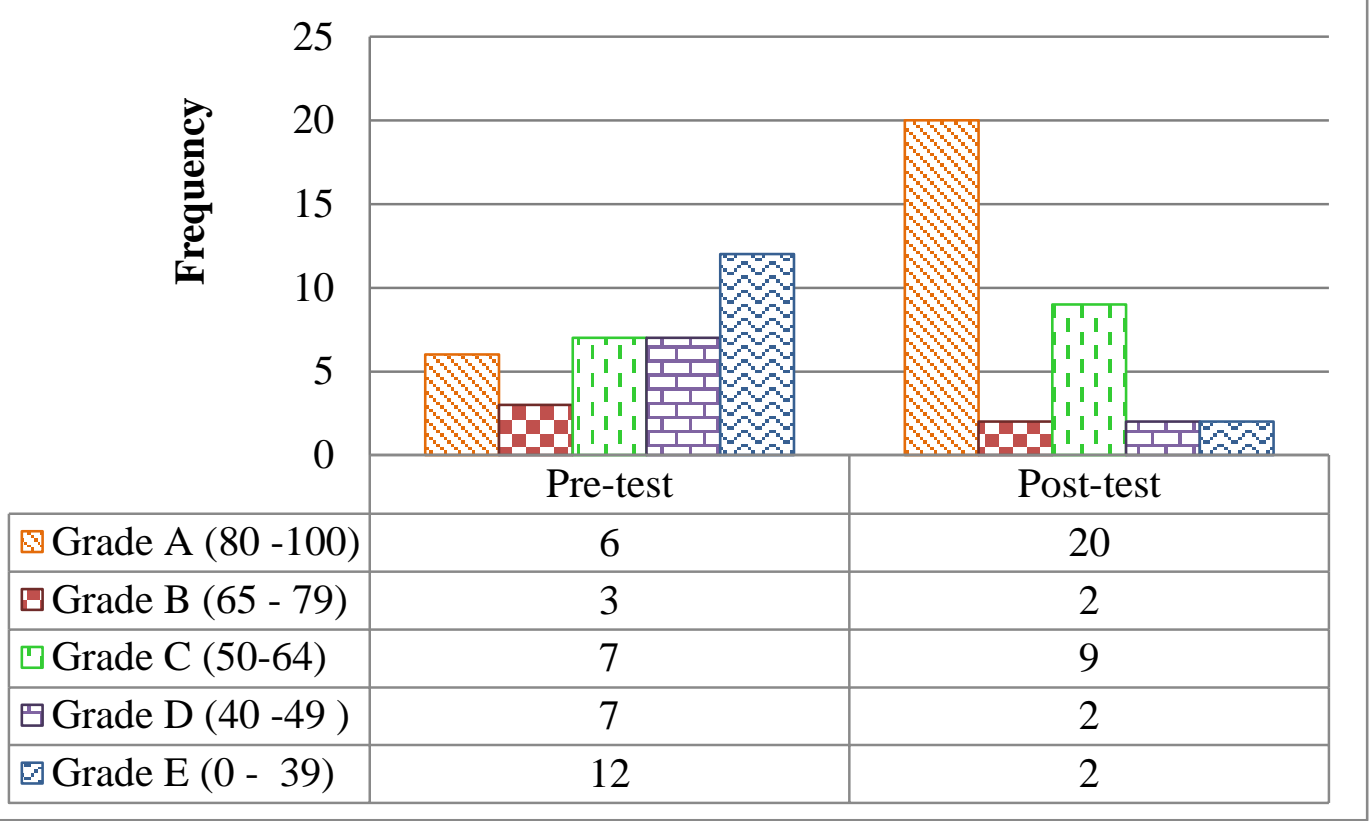

A comparison was done based on five categories of grading. The categories are as the following: Distinction (grade A), Good (grade B), Satisfactory (grade C), Weak (grade D) and Very Weak (grade E). This grading was adapted from the School Examination Analysis System (SAPS), Malaysian grading system. The analysis is tabulated in Figure 1. The graph in Figure 1 shows a significant increment in the number of pupils that received distinction. From Figure 1, there were only 6 pupils (17.1\%) who obtained a distinction in pre-test while 20 pupils (57.1\%) managed to score distinction in post-test. Apart from that, the number of pupils decreased in the Grade D and Grade E level of achievements where the differences of percentage were $14.3 \%$ and $28.6 \%$ respectively while the mean for both pre-test and post-test were 4.5 and 7.02 respectively. Moreover, the data was counted using inferential statistics and it showed that there were significant difference between the pre-test and post-test of the pupils before and after the use of the pupils' module. It was found that the scores in post-test $(M=7.05)$ were higher than the scores on pretest $(\mathrm{M}=4.5)$.

Results showed that there was an increase seen in the difference between the mean score from pre and the post-tests. This proved that with the help of visual aids, pupils were able to understand how to create sentences with the correct sentence structures. After learning by words for each emoji in Module 1, they were able to learn to combine two to four pictures to create a correct sentence where the subjects and verbs agree. This showed that pupils were learning to differentiate the difference between the verbs, adjectives and adverbs in a sentence and arrange them in a grammatically correct structure. 
However, from the works of the pupils there were a few things to be put into consideration. First, teachers should expect variance in the writings produced by the pupils. As they interpreted the emojis according to their own understanding, the answers for the writing exercises by one pupil might be different from another pupil. This is because these emojis can mean anything as long as the pupils can understand easily. A study conducted to investigate 210 undergraduates' interpretations of 75 smiley (face-like) meanings in WhatsApp Messenger found that even though the students interpreted the smiley correctly, they did not know the intended meaning of most of the smileys correctly (Subashini \& Sobihatun, 2017). A severe misinterpretation of messages and visual cues due to the difference in understanding of emojis could lead to communication breakdown (Tigwell \& Flatla, 2016) and in this case, the narrative writing. Therefore, it is best for the teacher to emphasize to the pupils that one emoji does not have to be fixed to one meaning. Second, they must be exposed to the Subject Verb Agreement in Module 2 clearly for them to be able to write sentences using the correct sentence structure later on. If not, only the structure of the sentence will be correct but it will not grammatically.

\section{Questionnaire}

Table 1:-Comparison of item means between the Before and After using Emojis Modules

\begin{tabular}{|l|l|c|c|}
\hline No. & Items & \multicolumn{2}{|c|}{ Mean } \\
\cline { 3 - 4 } & & \multicolumn{1}{|c|}{ Before } & After \\
\hline 1 & I know the sentence structure & 2.8 & 3.7 \\
\hline 2 & $\begin{array}{l}\text { The method used by the teacher today help me to write } \\
\text { sentences better. }\end{array}$ & 3.8 & 4.0 \\
\hline 3 & I am confident in writing sentences. & 4.3 & 4.7 \\
\hline 4 & Writing is hard. & 2.5 & 2.0 \\
\hline 5 & It is difficult to write narrative story & 2.7 & 3.0 \\
\hline
\end{tabular}

The data obtained from the questionnaire showed in Table 1. The mean for Item 1 structure' showed an increment of $90 \%$. The percentage of improvement after the emojis module from Item 2 and 3 were 20\% and $40 \%$ respectively. There was a decrease of $50 \%$ for the item 4 . A $30 \%$ increment of mean between before and after the intervention was shown in item 5 .

From the findings, the use of writing modules has helped the pupils to narrate stories better. This is shown from the data collected where there is an increasing understanding shown by the pupils in constructing sentences when emojis is used by the teacher. This suggested that the Emojis Modules had helped the pupils to construct correct sentence structures and narrate stories better. The data also indicated that pupils seemed to have higher confidence level in writing sentences when they were aided by emojis. As supported by Staden (2011), visual aids and multimedia are usually used as scaffolding for the pupils with different ways in different levels.

However, the findings also showed that pupils seemed to have showed an increment in the level of difficulty of writing narrative story. The result indicated that pupils still view writing narrative story as something that is difficult for them to do. This perhaps can be explained through the inadequate writing exercises provided in Module 3 for them to practice writing their narrative story. Hence, more narrative writing exercises should be added to Module 3 as a way to expand their imagination to creatively narrate their stories. Clay (2001) emphasized the importance of practice in writing because when the pupils were provided with sufficient vocabulary and experience in language use, they will have lower level of writing apprehension and perform better in their writing tasks.

\section{Interview}

Table 2:-Thematic coding from the post-intervention interview data

\begin{tabular}{|l|l|l|}
\hline No. & Categories of factors & $\%$ \\
\hline 1 & Teaching method facilitates writing stories & 29.2 \\
\hline 2 & Constructing sentences is easy & 20.8 \\
\hline 3 & Construct sentences is confusing & 16.7 \\
\hline 4 & Writing story is fun & 33.3 \\
\hline
\end{tabular}


\begin{tabular}{l|l} 
Total & 100
\end{tabular}

The $4^{\text {th }}$ Factor had $33.3 \%$ of emergence while $1^{\text {st }}$ Factor and $2^{\text {nd }}$ Factor had percentage of $29.2 \%$ and the later one was $20.8 \%$. The percentage that claimed constructing sentences is confusing was $16.7 \%$. There are $16.6 \%$ of differences between the lowest and highest emerging theme.

In the interviews, one of the pupils mentioned that through the use of the emojis helped him to improve his writing skills. Before the intervention was conducted, most pupils perceived writing lessons as boring and dull. However, pupils started to change their opinions after they had completed the three writing modules. With the aids of the emojis to help them to construct sentences and narrate stories, they are now having more fun during writing lessons. They get excited seeing pictures of emojis with colours which could be the reason why they found writing more fun compared to the traditional method. As pupils were very familiar with WhatsApp emojis, this could be the reasons why they became more motivated and confident in learning ESL writing. This statement was supported by Yunus, Salehi and Chen (2012), in a study conducted to explore the strengths and weaknesses of integrating social networking tools into ESL classroom. The findings revealed that integrating social networking tools (WhatsApp emojis) in ESL classroom could help to broaden pupils' knowledge, increase their motivation and build confidence in learning ESL writing. One of the pupils also mentioned how she felt more confident and less anxious during when writing narrative stories.

\section{Conclusion:-}

In conclusion, the intervention of using emojis in a modular approach found to be effective in improving narrative writing for low English language proficiency to certain extent. The use of the emojis module can be the extra teaching tool for teachers to teach and encourage pupils to engage in writing task thus enhancing their proficiency level. It is hoped that this innovation can assist pupils to 'visualize' the correct language structures of English and positive reinforcement in English writing lesson. At the same time, the knowledge can be practiced anywhere and at any time via any social network or online classes. It can even be done outside of the teaching and learning sessions. Hence, teachers should make use of this module in order to make writing lessons easier and effective, especially in narrative writing activities not only for Year 4 pupils but also for pupils of all range of age. The modules offer great flexibility as it not only be used in urban area schools but also in rural areas as there is a module being developed for this innovation. In the next cycle, teacher can choose either to use the module or simply use the social applications for pupils to learn writing.

\section{References:-}

1. Abraham, A. (2015): Action researching power in an ESL and academic writing classroom. Qualitative Research Journal, 15(2), 155-165.

2. Ajayi, L. (2008): Meaning-making, multimodal representation, and transformative pedagogy: An exploration of meaning construction instructional practices in an ESL high school classroom. Journal of Language, Identity, and Education, 7(3-4), 206-229. https://doi.org/10.1080/15348450802237822

3. Berkel, V. A. (2004): Learning to spell in English as a second language. IRAL, 42, 239-258. https://doi.org/ 10.1515/iral.2004.012

4. Clay, M. M. (2001): Change over time in children's literacy development. London: Heinmann Educational Books.

5. Danesi, M. (2017). The semiotics of Emoji: The rise of visual language in the age of the internet. London: Bloomsbury Pusblishing Plc.Fischer, C. (2003): Writing systems. An introduction to their linguistic analysis. Cambridge: Cambridge University Press.

6. Halwani, N. (2017): Visual Aids and Multimedia in Second Language Acquisition. English Language Teaching, 10(6),53-56. Available: ISSN 1916-4742.

7. Haq, F. S., Maarof, N. \& Musa, R. R. M. F. (2001). Masalah penulisan naratif di kalangan pelajar sekolah menengah [Problems in narrative writing among secondary school students]. Jurnal Pendidikan, 2, 3-26.

8. Lo, S. K. (2008). The nonverbal communication functions of emoticons in computer-mediated communication. CyberPsychology \& Behavior, 11(5), 595-597.

9. Noriati A. R., Boon P. Y. \& Wong K. W. (2010): Asas Kepimpinan dan Perkembangan Profesional Guru. Selangor: Oxford Fajar.

10. Stark, L. \& Crawford, K. (2015): The Conservatism of Emoji: Work, Affect, and Communication. Social MediaSociety. 1(2), 1-11. https://doi.org/10.1177/2056305115604853 
11. Said, N. E. M., Yunus, M., Doring, L. K., Asmi, A., Aqilah, F., \& Kwan, L. S. L. (2013). Blogging to enhance writing skills: A survey of students' perception and attitude. Asian Social Science, 9(16), 95-101. http://dx.doi.org/10.5539/ass.v9n16p95

12. Subashini, A \& Sobihatun, N. A. S. (2017): Undergraduates' Interpretation on Whatsapp Smiley Emoji. Universiti Utara Malaysia. Malaysian Journal of Communication. 33(4), 89-103.

13. Staden, V. A. (2011): Put reading first: Positive effects of direct instruction and scaffolding for ESL learners struggling with reading. Perspectives in Education, 29(4), 10-21.

14. SwiftKey. (2015): SwiftKey Emoji Report. United State: TouchType Limited.Tigwell, G. W., \& Flatla, D. R. (2016): "Oh that's what you meant!": Reducing emoji misunderstanding. Proceedings of the 18th InternationalConference on Human-Computer Interaction with Mobile Devices and Services Adjunct (pp. 859866). New York.

15. Tindal, G. A., \& Marston, D. B. (1990): Classroom-based Assessment: Evaluating Instructional Outcomes. Ohio: Merril.

16. UNICEF. (2017): The state of the world's children: Children in a digital world. New York, NY: United Nations Children's Fund (UNICEF).

17. Yunus, M. M., \& Salehi, H. (2012): The effectiveness of Facebook groups on Teaching and Improving Writing: Students' perceptions. Journal of Education and Information Technologies, 1(6), 87-96.

18. Yunus, M. M., Salehi, H., \& Chenzi, C. (2012): Integrating social networking tools into ESLwriting classroom: Strengths and weaknesses. English Language Teaching, 5(8), 42-48. http://dx.doi.org/10.5539/elt.v5n8p42

19. Yunus, M. M, Saleh, H. \& and Embi, M.A. (2012): Effects of Using Digital Comics to Improve ESL Writing. Research Journal of Applied Sciences, Engineering and Technology, 4(18): 34-62. Yunus, M.M \& Salehi, H. (2012). Tumblr as a Medium to Improve Students' Writing Skills. Journal of Applied Sciences Research, 8(1): 383-389.

20. Zakaria, S. M., Yunus, M. M., Nazri, N. M., \& Shah, P. M. (2016). Students' Experience of Using Storybird in Writing ESL Narrative Text. Creative Education, 7, 2107-2120. http://dx.doi.org/10.4236/ce.2016.715210 